\title{
TRANSACTIONAL DISTANCE AND AUTONOMY IN A DISTANCE LEARNING ENVIRONMENT
}

\author{
G.Vasiloudis_vasiloudisg@gmail.com],M.Koutsonba[makonba@phed.noa.gr],Y.Giossos \\ [xayiannis@gmail.com],I.Mavroidis_imavn@tee.gr],Hellenic Open University, Greece
}

\begin{abstract}
This paper studies the transactional distance between the students and the tutor as well as the autonomy of students in a postgraduate course of the Hellenic Open University (HOU). The aim of the paper is to examine how the relation between autonomy and transactional distance evolves during an academic year and how this relation is affected by demographic parameters, such as gender, age group and student experience (year of studies). For this purpose an empirical research was conducted and a sample of postgraduate students responded to a questionnaire (which included a scale for transactional distance, a scale for autonomy and demographic questions) during two different time periods within an academic (2012-2013). The results of the statistical analysis showed that during the evolution of the learning process there was a small change in transactional distance, especially for the dimension of co-understanding, while there was also a change in one of the dimensions of autonomy, namely sensitivity to others. However, no relation was observed between transactional distance and autonomy, ether in the first or the second measurement during the academic year. This finding is also regarded in the overall framework of the different critiques and interpretations of Moore's theory.
\end{abstract}

Key-words: transactional distance, autonomy, distance education

\section{Introduction}

According to Moore's theory (1993), the transactional distance between the teacher and the learner in distance learning is influenced by three variables: i) the dialogue that develops between the teacher and the learner, ii) the structure of the educational program, and iii) the autonomy of the learner. In particular, Moore states that the transactional distance is inversely proportional to the dialogue, i.e. the more the dialogue increases, the more the transactional distance decreases. On the other hand, transactional distance is proportional to the structure of the program as well as to the autonomy. This means that the more the structure of the program increases, the more the dialogue decreases, thus the transactional distance increases. It should be noted that, according to Moore, this is not absolute, since above a certain level the reduction of the structure of the program does not entail additional increase in the dialogue and therefore reduction of the transactional distance.

Autonomy is a characteristic of learners who are able to exert control on their learning and manage it in a self-reliant manner. It can be affected by the dialogue and the course's level of rigidity and flexibility as well as by the extent to which learners are able to control the learning process (Giossos et al., 2009). Garrison (2000) noted that learner autonomy cannot be easily explained, as it may be related to personal autonomy of the learner or autonomy linked with the learning materials themselves, while Kanuka et al. (2002) noted that both high and low levels of transactional distance may be accepted depending on the individual characteristics of each learner and his/her autonomy level. 
Moore's theory was tested empirically by many researchers (Bischoff, 1993; Bischoff et al., 1996; Saba, 1988; Saba \& Shearer, 1994; Chen, 1997, 2001a, 2001b; Chen \& Willits, 1998; Force, 2004; Starr-Glass, 2012), but with contradictory results. Gorsky and Caspi (2005) considered that the theory itself has problems in the conceptual definitions of the variables and for this reason the empirical results were contradictory. Despite these conflicting results, it constitutes an important theory that continues to attract research interest in distance education. Indeed, Giossos, Koutsouba, Lionarakis and Skavantzos (2009) suggested that any contradictions can possibly be overcome and that the theory can still be fruitful under two conditions: the first refers to the continuation of the theoretical process of the fundamental concepts and the second in joining the epistemological framework of critical realism. This is because realism does not address cause and effect relations, but conditions under which a result is manifested (Robson, 2002). On this basis, the emphasis is placed on the distance education framework and not on the cause and effect relation. In the present study the framework is the teaching process at the Hellenic Open University (HOU) that is characterized by the existence of a limited number of face-to-face Counseling Group Sessions (CGS), teacher-student communication in between meetings and the correction of written assignments and final written exams. Transactional distance at the Hellenic Open University has been examined in very few studies, e.g. Giossos (2009), Giossos, Koutsouba and Mavroidis (2011) Kassandrinou, Angelaki and Mavroidis (2014), yet without investigating the relation between transactional distance and autonomy.

The aim of this paper is to study the interaction between autonomy and transactional distance in a distance education environment. More specifically, the paper aims to study the relation between autonomy and transactional distance in the Hellenic Open University (HOU) and how this evolves during an academic year. Furthermore it examines how demographic parameters such as gender, age group and student experience (year of studies) in the HOU affect this relation.

\section{Method}

The research was conducted among 29 students of the Hellenic Open University (HOU) and, specifically, students of the postgraduate course module "Open and Distance Learning". For this purpose one questionnaire of 60 questions was given to the students. The questionnaire included: i) five (5) general demographic items relating to gender, age and educational level of the participants, ii) an evaluation scale of transactional distance containing 25 items and iii) the psychometric autonomy-connectedness scale by Bekker and van Assen (ACS-30) (2006) which consisted of thirty (30) questions. The scale of transactional distance was developed by Giossos (2009) and contained items that assessed two dimensions of Moore's theory of transactional distance, namely the dimension of co-understanding and the dimension of awareness (Giossos, 2009; Giossos, Koutsouba \& Mavroidis, 2011).

Specifically, of the 25 items, the first 10 indicated valid scores for the dimension of counderstanding and the remaining 15 items the dimension of awareness. The scale showed high reliability on the factor of co-understanding of cognitive skills (Cronbach's $a=.899$ ), on the factor of co-understanding of the emotional state (Cronbach's $a=.908$ ), on the factor of awareness of cognitive skills (Cronbach's $a=.955$ ) and on the factor of awareness of the emotional state (Cronbach's $a=.948)$. Results from the construct validity support an adequate fit of the two-factor model to the observed data $\left(\chi^{2}=113.725, \mathrm{p}<.01\right.$, Satorra-Bentler $\chi^{2}=69.784$, $\mathrm{p}<.001, \mathrm{df} 32, \chi^{2} / \mathrm{df}$ ratio $=2.181$, CFI $=.934$, IFI $=.935$, AGFI $=.813, \quad \mathrm{RMR}=.063$, RMSEA $=.113(90 \%$ CI of RMSEA $=.091-.135)$. The items of the autonomy scale assessed the self-awareness of the learner, the sensitivity the students have to the other people, and the capacity of managing new situations (Bekker \& van Assen, 2006). The scale also has high reliability both in the factor of self-awareness (Cronbach's $a=.81$ ), and the capacity of managing 
new situations (Cronbach's $a=.82$ ), as well as sensitivity to others (Cronbach's $a=.83$ ). Both scales in the psychometric questionnaire use the Likert scale with a rating of 1 to 5 .

The questionnaire was given for completion during the academic year 2012-2013 to two (2) faceto-face Counseling Group Sessions (CGS) of the postgraduate course module "Open and Distance Learning" of the Hellenic Open University in two different occasions. The first was the second CGS conducted nearly two months after the start of the ten-month teaching process. In this case, the questionnaire was completed by forty-six (46) students. Then, at the fourth CGS, conducted nearly six months after the start of the ten-month teaching process, the same questionnaire was completed by thirty-five (35) students. From those, twenty-nine (29) students were present in both occasions, thus allowing the examination of the temporal evolution of their responses. These twenty-nine (29) students are the final sample of the present study.

Based on the above, the following points should be taken into consideration regarding the limitations of the instrumentation as well as those of the overall research. The aforementioned instruments are self report ones. In addition, because of the number of the participants and the general research design, confirmatory factor analysis could not be conducted in order to estimate construct validity. Furthermore, the psychometric autonomy-connectedness scale by Bekker and van Assen (ACS-30) was developed in another educational and cultural context. Regarding the overall research, it should also be mentioned that the present study was conducted at two specific occasions during a postgraduate programme within the distance learning environment of HOU.

The following statistical methods were used: i) descriptive measures of central tendency, such as the mean and standard deviation for the assessment of all test variables, ii) a $t$-test for independent samples was conducted, for the differences of transactional distance based on gender on students' experience in the HOU, iii) a $t$-test for dependent samples was conducted for the differences of transactional distance between the CGS, iv) an analysis of variance of one-way was conducted for the differences based on students' age group, v) Pearson product-moment correlations were computed for testing the relationship of the dimensions of transactional distance with the dimensions of autonomy. The level of significance ( $p$-value) for all analyses was .05. The analysis was conducted using the statistical software SPSS for Windows 20.

\section{Results}

\section{Demographic characteristics}

From the twenty-nine (29) students, ten (10) or 34.48\% were male and nineteen (19) or $65.52 \%$, were female. In terms of their educational level, six (6) students or $20.69 \%$ had already obtained a master's degree, while twenty-three (23) or 79.31\% were university graduates. Finally, ten (10) of the participants were in the first year of their postgraduate studies in HOU, while the remaining nineteen (19) had completed at least one year of studies. Regarding the age of the participants, the results are presented in Table 1.

Table 1: Absolute and relative frequency of participants per age

\begin{tabular}{|l|c|c|c|}
\hline Age & f & f\% & Total \\
\hline 26 to 35 years old & 6 & $20.7 \%$ & $20.7 \%$ \\
\hline 36 to 45 years old & 11 & $37.9 \%$ & $58.6 \%$ \\
\hline 46 to 55 years old & 12 & $41.4 \%$ & $100.0 \%$ \\
\hline Total & 29 & $100.0 \%$ & \\
\hline
\end{tabular}




\section{Reliability}

The scale of transactional distance in the first measurement, namely in the second CGS, presented high reliability regarding the co-understanding of cognitive skills (Cronbach's $a=.87$ ) and the co-understanding of emotional state (Cronbach's $a=.96)$. In the second measurement, namely in the fourth CGS, the scale of transactional distance also showed high reliability, both regarding co-understanding of cognitive skills (Cronbach's $a=.92$ ) and the awareness of emotional state (Cronbach's $a=.97$ ). The scale of autonomy showed high reliability both in the first measurement $\left(2^{\text {nd }} \mathrm{CGS}\right.$ ) regarding sensitivity to the others (Cronbach's $a=.79$ ), capacity for managing new situations (Cronbach's $a=.76$ ) and self-awareness (Cronbach's $a=.79$ ), and in the second measurement $\left(4^{\text {th }} C G S\right)$ regarding sensitivity to the others (Cronbach's $a=.78$ ), managing new situations (Cronbach's $a=.75$ ) and self-awareness (Cronbach's $a=.81$ ).

\section{Results of the measurement at the $2^{\text {nd }}$ CGS}

The mean score $(M)$ of the dimension of co-understanding for the transactional distance in the five-point scale in the first measurement was 2.9897 (SD =.77060), while for the dimension of awareness it was $3.27(S D=.98)$. An independent-samples $t$-test was conducted to compare transactional distance between male and female students. There was not a significant difference in the scores of co-understanding between male students $(M=3.1300, S D=.79169)$ and female students $(M=2.92, S D=.77)(t(27)=.705,2$-tailed $p=.487)$. Additionally, there was not a significant difference in the scores of awareness between male students $(M=3.26, S D=.98)$ and female students $(M=3.27, S D=1.01)(t(27)=-.026,2$-tailed $p=.979)$. The difference in the mean scores $(M)$ of co-understanding and awareness among students regarding their age showed no significant difference either in co-understanding $(F(2,26)=2.257, p=.125)$ or awareness $(F(2,26)=3.075, p=.063)$. Finally, there was not a significant difference regarding their experience in HOU, either in co-understanding $(t(27)=-.198,2$-tailed $p=.845)$ or awareness $(t(27)=.286,2$-tailed $p=.777)$.

Regarding autonomy, the mean score $(M)$ for the sensitivity to the others in the five-point scale in the first measurement was $2.48(S D=.55)$, for the capacity for managing new situations were $3.20(S D=.82)$, while for self-awareness was $3.68(\mathrm{SD}=.80)$. There was not a significant difference for sensitivity to the others between male and female students $(t(27)=.489,2$-tailed $p=.629)$ as well as for the capacity for managing new situations $(t(27)=1.201,2$-tailed $p=.240)$ and self-awareness $(t(27)=.141,2$-tailed $p=.889)$. The results showed no significant difference in terms of age group, regarding the sensitivity to the others $(F(2,26)=.761, p=.477)$, the capacity of managing new situations $(F(2,26)=.392, \mathrm{p}=.680)$ and self-awareness $(F(2,26)=.007, p=.993)$. Finally, there was not a statistically difference for sensitivity to the others on the part of students who were in the first year of their postgraduate studies $(t(27)=.823,2$-tailed $p=.418)$. This was also the case regarding the capacity of managing new situations $(t(27)=.626,2$-tailed $p=.536)$. Only the mean scores for self-awareness were significantly different $(t(27)=2.234,2$-tailed $p=.034)$. Table 2 shows that the dimensions of transactional distance and the dimensions of autonomy where uncorrelated $p>.05$

Table 2: Correlations between transactional distance and autonomy dimensions for the $1^{\text {st }}$ measurement

\begin{tabular}{|l|c|c|}
\hline & Co-understanding1 & Awareness1 \\
\hline Managing1 & .28 & .06 \\
\hline Self-awareness1 & -.08 & -.23 \\
\hline Sensitivity1 & -.15 & .07 \\
\hline
\end{tabular}




\section{Results of the measurement at the $4^{\text {th }}$ CGS}

The mean score $(M)$ of the dimension of co-understanding for transactional distance in the fivepoint scale in the second measurement was $3.35(S D=.79)$, while for the dimension of awareness it was $3.37(S D=.92)$. There was not a significant difference in the scores for counderstanding between male students $(M=3.56, S D=.61)$ and female students $(M=3.24$, $S D=.87) \quad(t(27)=1.025$, 2-tailed $p=.314)$ and for awareness between male students $(M=3.6667, S D=.87970)$ and female students $(M=3.20, S D=.95)(t(27)=1.292,2$-tailed $p=.207)$. Moreover, there was not a significant difference in the scores for co-understanding $(F(2,26)=2.506, p=.101)$ and for awareness $(F(2,26)=2.657, p=.089)$ based on students' age group. Finally, there was not a significant difference regarding students' experience in HOU both for co-understanding $(t(27)=-.105,2$-tailed $p=.917)$ and awareness $(t(27)=.116,2$-tailed $p=.909)$.

Regarding autonomy, the mean score $(M)$ for sensitivity to the others in the five-point scale in the second measurement was $2.65(S D=.54)$, for the capacity in managing new situations 3.25 $(S D=.86)$ and for self-awareness $3.71(S D=.75)$. There was not a significant difference in the scores for sensitivity to the others $t(27)=.404,2$-tailed $p=.689)$ based on gender. This was also the case for the capacity of managing new situations $(t(27)=.287,2$-tailed $p=.777)$ and for selfawareness $(t(27)=-.414,2$-tailed $p=.682)$.

The results showed no significant difference regarding the age group for the sensitivity to others $(F(2,26)=.327, p=.724)$, the capacity for managing new situations $(F(2,26)=.832, p=.447)$ and self-awareness $(F(2,26)=.327, p=.724)$. Finally, there was not a significant difference for sensitivity to others $(t(27)=.433,2$-tailed $p=.668)$ based on students' experience. This was also the case regarding the capacity of managing new situations $(t(27)=.820$, 2-tailed $p=.420)$. On the other hand, there was a significant difference in the scores for self-awareness $(t(27)=2.159$, 2 -tailed $p=.040)$. Table 3 shows that the dimensions of transactional distance and the dimensions of autonomy where uncorrelated $p>.05$.

Table 3: Correlations between transactional distance and autonomy dimensions for the $2^{\text {nd }}$ measurement

\begin{tabular}{|l|c|c|}
\hline & Co-understanding2 & Awareness2 \\
\hline Managing2 & .11 & .23 \\
\hline Self-awareness2 & -.02 & -.09 \\
\hline Sensitivity2 & -.02 & -.07 \\
\hline
\end{tabular}

**. Correlation is significant at the 0.01 level (2-tailed).

\section{Differences of transactional distance and autonomy in relation to the evolution of CGS}

A dependent-samples $t$-test was conducted to compare transactional distance between the two CGS. There as a significant difference in the scores for co-understanding in the second CGS $(M=2.99, S D=.77)$ and in the fourth CGS $(M=3.35, S D=.79)(t(28)=-2.640,2$-tailed $p=.013)$. On the other hand, there was not a significant difference in the scores for awareness among postgraduate students in the second CGS $(M=3.27, \mathrm{SD}=.984)$ and in the fourth CGS $(M=3.37, S D=.92)(t(28)=-.657,2$-tailed $p=.517)$.

Regarding autonomy, there was a significant difference in the scores for sensitivity to others in the second CGS $(M=2.48, S D=.55)$ and in the fourth CGS $(M=2.65, S D=.54),(t(29)=$ 2.143, 2-tailed $p=.041)$. On the other hand, there was not a significant difference in the scores for the capacity in managing new situations in the second CGS $(M=3.20, S D=.82)$ and in the 
fourth CGS $(M=3.25, S D=.85),(t(28)=-530,2$-tailed $p=.600)$. Additionally, there was not a significant difference in the scores for self-awareness in the second CGS $(M=3.68, S D=.80)$ and in the fourth CGS $(M=3.7, S D=.75),(t(28)=-.233,2$-tailed $p=.818)$.

\section{Discussion}

Based on the results, it can be argued that even at the second CGS, transactional distance has been limited, regarding both the dimension of co-understanding and the dimension of awareness. However, the distance of co-understanding was larger than the distance of awareness. The question is why, is this happening. Probably this might be expected because between the students and the tutors there are differences in the level of knowledge and, therefore, in their perceptions regarding the subject matter of the course module. The results of the second measurement $\left(4^{\text {th }}\right.$ CGS) confirm the findings from the first measurement $\left(2^{\text {nd }}\right.$ CGS $)$ on the transactional distance as a whole. However, in this case the distance of co-understanding and the distance of awareness are at the same level, which is expected as the students are more familiar with the subject matter at the $4^{\text {th }}$ CGS. The fact that from the beginning there is limited transactional distance between the students and the tutor may also be attributed to the majority of the postgraduate students having some sort of relationship with education (e.g., as primary and secondary teachers). Therefore they may have a specific approach to educational processes.

For the assessment of student autonomy, it is indicated from the results of the first measurement that higher values are observed regarding the dimensions of managing new situations and selfawareness in relation to the dimension sensitivity to others. It can be concluded that from the beginning of the academic year, students appear to have high levels of self-awareness and capacity to manage new situations. This is expected, since on the one hand they are adult students and on the other hand they have previous university experience, since they attend a postgraduate programme. On the contrary, the dimension of sensitivity to others does not show significantly positive value. This can be explained by the fact that the $2^{\text {nd }}$ CGS is at the beginning of the academic year and the students have not yet developed such feelings, while the sense of community has not yet been totally formed. Based on the findings of the second measurement $\left(4^{\text {th }}\right.$ CGS), the values of the three dimensions of student autonomy are similar. This is expected, since as the academic year progresses, the sensitivity to others increases.

Regarding the relation between transactional distance and autonomy, the findings showed that it was very limited. In other words, the results of this study do not prove a clear relation between transactional distance and autonomy, for any of their dimensions, which is consistent with the findings of previous studies (Chen \& Willits, 1998; Chen, 2001; Force, 2004; Starr-Glass, 2012). Does this mean that Moore's theory is not confirmed during the present study? One conceivable answer is yes, especially since there are a lot of empirical studies with the same results, forming the basis of several critiques for Moore's theory (see Gorsky \& Caspi, 2005; Giossos et al., 2009). The main point raised there, is that it is very difficult to try and explain human behaviours and emotions applying a purely quantitative approach used by the exact sciences. On the other hand, there are also potential alternative explanations. First of all, it is possible that those results are due to the psychometric autonomy-connectedness scale. As has been mentioned, this scale was not developed for this specific educational and cultural context. Another probable explanation is that there is a moderator that alters the direction or strength of the relationship between transactional distance and autonomy. Such moderator could be, for example, the students' learning styles. Of course, the previous explanation was not the subject of this study and could provide scope for further research.

The findings from both measurements showed no differences in the transactional distance in terms of gender, age and student experience (year of studies) in the HOU. These findings are 
consistent with the research of Huang (2002) and Force (2004) with respect to gender, as well as with the research of Force (2004) regarding the age group. The findings on autonomy also showed no differences in relation to the demographic characteristics. This is different from the results of Bekker (1993), Bekker and van Assen (2006), Bekker and Belt (2006), Bekker et al. (2001) and Bekker et al. (2007), who detected a significant difference between genders regarding the dimension sensitivity to others, where higher values were observed for women. In addition, in the study of Bekker and van Assen (2008), apart from the gender differences in relation to sensitivity to others, there were also small gender differences in the two other dimensions of autonomy, namely managing new situations and self-awareness. In this case, higher values were observed for men, which is not the case in the present study.

\section{Conclusions}

The present study examined the relation between transactional distance and autonomy in the distance learning environment of Hellenic Open University and how this evolves during an academic year. It was found that there was a small change in transactional distance between the $2^{\text {nd }}$ and the $4^{\text {th }} \mathrm{CGS}$, especially for the dimension of co-understanding, due to the evolution of the learning process. It was also found that there was a change in one of the dimensions of autonomy, namely sensitivity to others, due to the evolution of the learning process and the development of the student community. However, no relation was observed between transactional distance and autonomy, either in the first or in the second measurement. Consequently, it can be argued that there is little evidence that the learning process affects the relation between transactional distance and autonomy, at least within the framework of the Hellenic Open University. This could also regarded in the overall framework of the different critiques and interpretations of Moore's theory.

It should be noted that the findings of the present study could be verified -or not- in the future, through the use of other research methods such as observation. Furthermore, the ecological validity of the autonomy-connectedness scale by Bekker and van Assen (ACS-30) could be tested in the distance learning environment of HOU. It would be also interesting to examine the relation between transactional distance and autonomy in different than HOU types of distance learning environments, at more and/or different occasions during the evolution of the studies so as to examine further the evolution of the processes. Finally, a larger sample from more and different courses, both under and postgraduate could be used. In any case, the present study, as every research, opens up the way to a number of different future research questions.

\section{References}

1. Bekker, M.H.J. (1993). The development of an Autonomy scale based on recent insights into gender identity. In European Journal of Personality, 7, (pp. 177-194).

2. Bekker, M.H.J.; Bachrach, N.; Croon, M.A. (2007). The relationships of antisocial behavior with attachment, autonomy-connectedness, and alexithymia. In Journal of Critical Psychology, 63(6), (pp. 507-527).

3. Bekker, M.H.J. and Belt, U. (2006). The role of autonomy-connectedness in anxiety and depression. In Depression and Anxiety, 23, (pp. 274-280).

4. Bekker, M.H.J.; Hens, G.; Nijssen, A. (2001). Stress prevention training; Sex differences in types of stressors, coping, and training effects. In Stress and Health, 17, (pp. 207-218).

5. Bekker, M.H.J. and van Assen, M.A.L.M. (2006). A short form of the Autonomy scale: Properties of the Autonomy-Connectedness Scale. In Journal of Personality Assessment, 86, (pp. 51-60). 
6. Bekker, M.H.J. and van Assen, M.A.L.M. (2008). Autonomy-Connectedness and Gender. In Sex Roles, 59, (pp. 532-544).

7. Bischoff, W.R. (1993). Transactional distance, interactive television, and electronic mail communication in graduate public health and nursing courses: Implications for professional education. Unpublished doctoral dissertation. University of Hawaii, Honolulu.

8. Bischoff, W.R.; Bisconer, S.W.; Kooker, B.M.; Woods, L.C. (1996). Transactional distance and interactive television in the distance education of health professionals. In American Journal of Distance Education, 10(3), (pp. 4-19).

9. Chen, Y.J. (1997). The implications of Moore's theory of transactional distance in a videoconferencing learning environment. Unpublished doctoral dissertation. The Pennsylvania State University, Pennsylvania.

10. Chen, Y.J. (2001a). Transactional distance in world wide web learning environments. In Innovations in Education and Teaching International, 55(4), (pp. 327-338).

11. Chen, Y.J. (2001b). Dimensions of transactional distance in world wide web learning environment: A factor analysis. In British Journal of Educational Technology, 52(4), (pp. 459-470).

12. Chen, Y.J. and Willits, F.K. (1998). A path analysis of the concepts in Moore's theory of transactional distance in a videoconferencing learning environment. In The American Journal of Distance Education, 13(2), (pp. 51-65).

13. Force, D. (2004). Relationships among transactional distance variables in asynchronous computer conferences: A correlational study. Unpublished master thesis. Athabasca University, Athabasca.

14. Garrison, R. (2000). Theoretical challenges for Distance Education in the $21^{\text {st }}$ century: A swift from structural to transactional issues. In The International Review of Research in Open and Distance Learning, 1(1). Available at http://www.irrodl.org/index.php/irrodl/article/viewFile/2/22

15. Giossos, I. (2009). Validity and reliability for transactional distance scales in the Hellenic Open University. Master dissertation. School of Humanities, Hellenic Open University, Patras.

16. Giossos, Y.; Koutsouba, M.; Lionarakis, A.; Skavantzos, K. (2009). Reconsidering Moore's transactional distance theory. In European Journal of Open Distance and ELearning, 2009/II. Available at http:/ / www.eurodl.org/?p=archives\&year=2009\&halfyear=2\&article $=374$

17. Giossos, I.; Koutsouba, I.M.; Mavroidis, I. (2011). Validating a scale for transactional distance in distance education. In A. Lionarakis (ed.), Alternative Forms of Education, Proceedings of the 6th International Conference on Open and Distance Learning, (pp. 303-310). Available at http://icodl.openet.gr/index.php/icodl/2011/schedConf/presentations

18. Gorsky, A. and Caspi, A. (2005). A critical analysis of transactional distance. In The Quarterly Review of Distance Education, 6(1), (pp. 1-11).

19. Huang, H.M. (2002). Student perceptions in an online mediated environment. In International Journal of Instructional Media, 29(4), (pp. 405-422).

20. Kanuka, H.; Collet, D.; Caswell, C. (2002). University instructor perceptions of use of asynchronous text-based discussion in distance courses. In The American Journal of Distance Education, 16(3), (pp. 151-167).

21. Kassandrinou, A.; Angelaki, Ch.; Mavroidis, I. (2014). Transactional distance among open university students. How does it affect the learning process. In European Journal of Open, Distance and e-Learning, 17(1), (pp. 26-42). Available at http://www.eurodl.org/materials/contrib/2014/Kassandrinou_et_al.pdf 
22. Moore, M.G. (1993). Theory of transactional distance. In D. Keegan (ed.), Theoretical principles of distance education, (pp. 22-38). Routledge, New York.

23. Robson, C. (2002). Real world research ( $2^{\text {nd }}$ ed.). Wiley-Blackwell, Massachusetts.

24. Saba, F. (1988). Integrated telecommunication systems and instructional transaction. In American Journal of Distance Education, 2(3), (pp. 17-24).

25. Saba, F. and Shearer, R. (1994). Verifying key theoretical concepts in a dynamic model of distance education. In The American Journal of Distance Education, 9(1), (pp. 36-59).

26. Starr-Glass, D. (2012). Learners perceptions of distance in an online course: revisiting Moore's theory of transactional distance. Unpublished paper. 